\title{
Application of Structural Equation Models to Genome-wide Association Analysis
}

\author{
Jiyoung Kim', Junghyun Namkung ${ }^{2}$, Seungmook \\ Lee $^{1}$ and Taesung Park ${ }^{1 *}$
}

${ }^{1}$ Department of Statistics, Seoul National University, Seoul 151-747, Korea, ${ }^{2}$ Department of Epidemiology and Biostatistics, Case Western Reserve University, 2103 Cornell Road, Cleveland, OH 44106-7281, USA

\begin{abstract}
Genome-wise association studies (GWASs) have become popular approaches to identify genetic variants associated with human biological traits. In this study, we applied Structural Equation Models (SEMs) in order to model complex relationships between genetic networks and traits as risk factors. SEMs allow us to achieve a better understanding of biological mechanisms through identifying greater numbers of genes and pathways that are associated with a set of traits and the relationship among them. For efficient SEM analysis for GWASs, we developed a procedure, comprised of four stages. In the first stage, we conducted single-SNP analysis using regression models, where age, sex, and recruited area were included as adjusting covariates. In the second stage, Fisher's combination test was conducted for each gene to detect significant genes using $p$-values obtained from the single-SNP analysis. In the third stage, Fisher' $s$ exact test was adopted to determine which biological pathways were enriched with significant SNPs. Finally, based on a pathway that was associated with the four traits in common, a SEM was fit to model a causal relationship among the genetic factors and traits. We applied our SEM model to GWAS data with four central obesity related traits: suprailiac and subscapular measures for upper body fat, BMI, and hypertension. Study subjects were collected from two Korean cohort regions. After quality control, 327,872 SNPs for 8842 individuals were included in the analysis. After comparing two SEMs, we concluded that suprailiac and subscapular measures may indirectly affect hypertension susceptibility by influencing BMI. In conclusion, our analysis demonstrates that SEMs provide a better understanding of biological mechanisms by identifying greater numbers of genes and pathways.
\end{abstract}

*Corresponding author: E-mail tspark@stats.snu.ac.kr Tel +82-2-880-8924, Fax +82-2-883-6114 Accepted 2 September 2010
Keywords: central obesity, suprailiac, subscapular, body mass index (BMI), hypertension, genome-wide association study (GWAS), structural equation model (SEM), gene-based analysis, pathway-based analysis

\section{Introduction}

Genome-wide association studies (GWAS) are one of the major tools used to detect disease susceptibility loci. They have been successful in identifying associations of hundreds of single nucleotide polymorphism (SNPs) with complex traits (Rioux et al., 2007; Saxena et al., 2007; WTCCC, 2007; Zanke et al., 2007). However, testing only for the association of individual SNPs has limitations in unveiling the complex mechanism of genetic structures for complex traits (Lesnick et al., 2007). Dissecting biological phenomena and understanding the structure of the complex components comprising a biological pathway are challenging tasks. Commonly, GWASs have reported several significant SNPs from individual SNP analyses. However, complex traits are affected by the joint action of various genes. If only the significant SNPs from the individual SNP analysis are considered, the genetic variants that have joint action in determining traits with small individual contributions will be neglected.

Furthermore, the functions of SNPs are not well conceived in many cases, but the functions of genes and pathways have been better explored. Therefore, geneand pathway-based analysis provides an easier interpretation to unravel the mechanisms of complex traits (Baranzini et al., 2009; Kraft and Raychaudhuri, 2009; Rajagopalan and Agarwal, 2005). Most complex traits arise from complex interactions among multiple genetic factors and environmental factors.

In this study, we applied Structural Equation Models (SEMs) in order to model complex relationships between genetic networks and traits as risk factors (Bollen, 1989). The SEM was originally developed in the field of social science to fit a model with unobserved variables. It is well known that the main advantage of the SEM approach is that it allows us to compare several candidate models. Our application of the SEM to a GWAS enables us to investigate how each risk factor affects a targeted trait directly or through other variables, and SEM is used to represent the relationship among multiple phenotypes. In order to choose the components 
used to build a model, it is desirable to consider a higher level of genetic components, such as gene and biological pathways.

However, due to the enormous number of SNPs in a GWAS, it is practically difficult to apply SEMs to GWAS data. Thus, some step-wise procedure for filtering out SNPs is required in order to reduce the burden of computation. Our proposed procedure comprises four stages. At the first stage, single SNP association tests are conducted. The next step is to combine P-values for correlated SNPs in order to represent a gene by using Fisher's combination test (Zaykin et al., 2007). Next, Fisher's exact test is employed to find the association of a pathway related with the traits. Finally, SEMs are used to model how each risk factor influences the trait of interest based on the pathway chosen from the previous stages.

The proposed SEM approach is applied to a large-scale GWA dataset (i.e., 8842 samples and 327,872 SNPs), obtained from a Korean population. Especially, our analysis focuses on identifying the relationship between hypertension, obesity, and genetic variants. In hypertension, it is known that greater fatness or obesity in the extreme is associated with greater blood pressure or hypertension in the extreme (Dustan, 1991). Understanding the connections between hypertension and relative obesity is an important step in understanding the biological mechanism between them and providing useful information for the potential treatment. Central body fat distribution is especially associated with hypertension and insulin resistance (Licata et al., 1994; Scaglione et al., 1995). In this study, we investigated the genetic components associated with four central obesity-related traits by conducting the proposed four-stage analysis for large-scale GWAS data. Our GWAS data were collected from the participants of two cohort regions in Korea. The four traits used for analyses were suprailiac, subscapular, BMI, and hypertension. BMI is used for whole-body obesity, and suprailiac and subscapular represent upper central body fatness.

\section{Methods}

\section{Study subjects}

The data were collected from a Korea Association Resource (KARE) project that was initiated in 2007 to undertake a large-scale GWA analysis. The 10,038 participants were recruited from two community-based cohorts: Ansung, representing mainly a rural community, and Ansan, representing an urban community--5018 from Ansung and 5,020 from Ansan, aged between 40 and 69 years old (Cho, et al., 2009) (Table 1). A total of 8800 participants (4162 men and 4638 women) were included for the GWAS analysis, excluding those who were taking medicine or therapy for lipoprotein levels.

\section{Genotyping and quality control}

The DNA samples were isolated from the peripheral blood of participants and genotyped using the Affymetrix Genome-Wide Human SNP array 5.0. The Bayesian Robust Linear Modeling using Mahalanobis Distance (BRLMM) was used for genotype calling. Standard data quality control procedures were applied for the subjects and SNPs, as described in Cho et al. (2009). After consideration of the sample and SNP quality controls, a total of 8842 participants and 352,228 SNPs remained for the subsequent analysis.

\section{Obesity-related traits}

In this study, four traits were considered: subscapular, suprailiac, body mass index (BMI), and hypertension. Subscapular and suprailiac values are skinfold thickness measurements for upper central body fat distribution around the waist. The subscapular measure is a vertical fold taken one inch to the side of the umbilicus from the abdominal. The suprailiac measure is a diagonal fold taken midway between the hip joint and the bottom of the rib cage. BMI is defined as the individual's body weight divided by the square of his or her height. Hypertensive status was defined as a SBP $<140 \mathrm{~mm}$ $\mathrm{Hg}$ and/or DBP $<90 \mathrm{~mm} \mathrm{Hg}$, and the blood pressure was measured in the supine position. One of the well-known risk factors of cardiovascular diseases is obesity. Especially, multiple studies have reported that abdominal obesity is a better predictor of hypertension rather than whole body fat mass (Niskanen et al., 2004; Selby et al., 1989).

\section{Statistical analysis of genetic association}

For each SNP, genetic association analyses were con-

Table 1. Demographic information of study subjects

\begin{tabular}{lc}
\hline \multicolumn{1}{c}{ Features } \\
\hline Total individuals & 8842 \\
Gender (male/female) & $4183(47 \%) / 4659(53 \%)$ \\
Area (ansung/ansan) & $4205(48 \%) / 4637(52 \%)$ \\
Age & $52.22^{1}( \pm 8.91)$ \\
Body mass index (BMI) & $24.59( \pm 3.12)$ \\
Subscapular skinfold (mm) & $23.69( \pm 10.96)$ \\
Suprailiac skinfold (mm) & $25.70( \pm 11.72)$ \\
\hline
\end{tabular}

${ }^{1}$ Mean ( \pm Standard deviation). 
ducted for individual phenotypes independently using three linear regression models for quantitative traits and a logistic regression model for hypertension. Age, sex, and recruited area (Ansan or Ansung) were included as adjusting covariates in all of the regression models. An additive allelic effect was assumed for the mode of genetic inheritance. Association analyses were conducted using PLINK software (Purcell et al., 2007).

Next, gene-based association tests were conducted using Fisher's combination test on the set of p-values obtained from the SNPs within a gene. The statistic $\left(Z_{\mathrm{F}}\right)$ for $K \mathrm{p}$-values obtained from $K \mathrm{SNPs}$ in a gene is given by:

$$
Z_{F}=-2 \sum_{i=1}^{K} \log P_{i}
$$

which follows a $\chi_{2 \mathrm{~K}}^{2}$ distribution when the $\mathrm{K}$ P-values are independent (Fisher 1925).

Thirdly, Fisher's exact test, based on the hypergenometric distribution, was employed to search for biological pathways that were enriched in the significantly associated genes. Let $N$ be the total number of genes that are of interest; $S$ be the number of genes that are significantly associated with the disease (nominal P-value $\leq 0.05$, by Fisher's combination test), and $\mathrm{i}$ and $\mathrm{m}$ represent the genes in the pathway and significantly associated genes in the pathway, respectively. The significance of the overrepresentation of a biological pathway is calculated by:

$$
P=1-\sum_{i=0}^{K} \frac{\left(\begin{array}{l}
S \\
i
\end{array}\right)\left(\begin{array}{l}
N-S \\
m-i
\end{array}\right)}{\left(\begin{array}{l}
N \\
m
\end{array}\right)}
$$

\section{Combinatorial analysis using SEMs}

SEMs are comprehensive statistical models that allow us to test relations among observed and latent (not observed directly) variables. The SEMs for our genetic networks were defined as follows:

$$
\begin{aligned}
& \mathrm{y}=\Lambda_{\mathrm{y}} \eta+\varepsilon, \\
& \eta=\mathrm{B} \eta+\mathrm{c}_{\mathrm{s}},
\end{aligned}
$$

where $y$ is a vector representing the observed variables; $\eta$ is a vector of the latent variables (pathway); $\Lambda_{\mathrm{y}}$ is a matrix representing the true relationships between the SNP and pathway; and $B$ is a matrix representing the true relationships among the latent variables. Random errors in the equations are represented by $\varepsilon$ and ç. To fit this model, we used AMOS, a SEM software solution provided by SPSS (http://www.spss.com/ amos/).

\section{Results}

\section{Single-SNP analysis using regression models}

Of 10,038 participants recruited from two Korean cohort areas, 8800 individuals were included to analyze the association between genetic variants and four central obesity-related traits: suprailiac, subscapular, BMI, and hypertension. The association between each of the 327,872 SNPs and each trait was evaluated via a regression model, adjusted for gender, age, and recruitment area. We used a significance level corresponding to $p$-value $<1.0 \mathrm{e}-5$ to determine which SNPs were associated with a trait. The detailed results are in Table 2 .

For suprailiac, 20 SNPs resulted in a significant association. Of these, rs16906215 in TLR4 showed the strongest association. The TLR4 gene encodes a toll-like receptor protein, which is an important member of the innate immune response. This gene has been reported to be associated with type 2 diabetes (Kolz, 2008). However, the effect of a SNP located far downstream of a gene is hard to interpret.

For subscapular, 5 SNPs from 4 genes met the significance criteria. The four genes are GRIN2A, NBPF21P, LOC1001131027, and FTO, and two SNPs from FTO were identified to be significant. FTO is one of the popular genes that are associated with fat mass and obesity. The rs9939609 allele in the FTO gene was previously reported to be positively related with BMI (Frayling et al., 2007; Willer et al., 2009) and type 2 diabetes (WTCCC, 2007). Rs9939609 also showed a marginally significant association with subscapular, producing a p-value of $1.14 \mathrm{e}-05$ and a significant association with BMI in our analysis. The most significant SNP was located upstream of the NMDA receptor (GRIN2A) gene, and GRIN2A was reported to be correlated with hypertension from a previous GWAS data analysis (Torkamani et al., 2008).

In the analysis of hypertension, four significant SNPs were detected from three genes: ATP2B1, CSK, and PTPN11. The results of ATP2B1 and CSK reproduced the significant relationships between variants of the genes and hypertension that had been previously reported by Hong et al., (2010). In their study, they conducted a meta-analysis using two cohort studies in Korea, including KARE (Hong et al., 2010). ATP2B was also reported to be associated with hypertension in another study (Levy et al., 2009). The key function of ATP2B1 is to control homeostasis of cellular calcium ion levels, which are related with vascular smooth muscle contraction and dilation. 
Table 2. SNPs significantly associated with central obesity-related traits

\begin{tabular}{|c|c|c|c|c|c|c|}
\hline RS number & Chr & P-value & MAF & Gene Symbol ${ }^{1}$ & Distance & Description \\
\hline \multicolumn{7}{|l|}{ Suprailiac } \\
\hline rs16906215 & 9 & $1.68 \mathrm{E}-07$ & 0.025 & TLR4 & 66,490 & down $70 \mathrm{k}$ \\
\hline rs7681841 & 4 & $7.48 \mathrm{E}-07$ & 0.012 & FBXO8 & 0 & intron \\
\hline rs10090537 & 8 & $9.80 \mathrm{E}-07$ & 0.011 & RIMS2 & 0 & intron \\
\hline rs3856726 & 3 & $1.34 \mathrm{E}-06$ & 0.012 & ATG3 & 97,246 & up $100 \mathrm{k}$ \\
\hline rs 4472504 & 8 & 1.36E-06 & 0.033 & ZMAT4 & 0 & intron \\
\hline rs17109716 & 14 & 1.89E-06 & 0.032 & NRXN3 & 0 & intron \\
\hline rs1510447 & 8 & $2.13 \mathrm{E}-06$ & 0.232 & SGCZ & 0 & intron \\
\hline rs601619 & 18 & $2.16 \mathrm{E}-06$ & 0.012 & CCDC102B & 0 & intron \\
\hline rs4745034 & 9 & $4.08 \mathrm{E}-06$ & 0.029 & TRPM3 & 0 & intron \\
\hline rs17599042 & 12 & $4.89 \mathrm{E}-06$ & 0.034 & MUC19 & 41,221 & down $50 \mathrm{k}$ \\
\hline rs1570064 & 6 & $5.25 \mathrm{E}-06$ & 0.015 & RHAG & 37,578 & up $40 \mathrm{k}$ \\
\hline rs11876341 & 18 & $6.01 \mathrm{E}-06$ & 0.098 & MEX3C & 76,301 & up $80 \mathrm{k}$ \\
\hline rs17168600 & 7 & $6.05 \mathrm{E}-06$ & 0.036 & LOC100128217 & 0 & intron \\
\hline rs2210977 & 1 & $6.86 \mathrm{E}-06$ & 0.019 & MARK1 & 0 & intron \\
\hline rs7583940 & 2 & $7.03 \mathrm{E}-06$ & 0.068 & LRPPRC & 32,425 & up $40 \mathrm{k}$ \\
\hline rs6965746 & 7 & 7.47E-06 & 0.309 & SLC25A13 & 77,756 & up $80 \mathrm{k}$ \\
\hline rs17226252 & 5 & $8.74 \mathrm{E}-06$ & 0.017 & & $16,777,215$ & \\
\hline rs3103261 & 2 & $9.25 \mathrm{E}-06$ & 0.02 & DIS3L2 & 0 & intron \\
\hline rs1849809 & 4 & $9.33 \mathrm{E}-06$ & 0.245 & MGC48628 & 0 & intron \\
\hline rs7010545 & 8 & $9.76 \mathrm{E}-06$ & 0.235 & SGCZ & 0 & intron \\
\hline \multicolumn{7}{|l|}{ Subscapular } \\
\hline rs16951883 & 16 & $1.06 \mathrm{E}-06$ & 0.018 & GRIN2A & 42,168 & up $50 \mathrm{k}$ \\
\hline rs17248901 & 3 & $2.66 \mathrm{E}-06$ & 0.03 & NBPF21P & 9,941 & down $10 \mathrm{k}$ \\
\hline rs6561930 & 13 & $3.36 \mathrm{E}-06$ & 0.013 & LOC100131027 & 36,359 & down $40 \mathrm{k}$ \\
\hline rs7193144 & 16 & 8.94E-06 & 0.126 & FTO & 0 & intron \\
\hline rs8050136 & 16 & $9.01 \mathrm{E}-06$ & 0.126 & FTO & 0 & intron \\
\hline \multicolumn{7}{|l|}{$B M I$} \\
\hline rs17178527 & 6 & $2.24 \mathrm{E}-08$ & 0.25 & LOC729076 & 97,011 & down $100 \mathrm{k}$ \\
\hline rs9939609 & 16 & $1.43 \mathrm{E}-06$ & 0.127 & FTO & 0 & intron \\
\hline rs 11000212 & 10 & $1.45 \mathrm{E}-06$ & 0.206 & DDIT4 & 78,025 & up $80 \mathrm{k}$ \\
\hline rs9926289 & 16 & $2.45 \mathrm{E}-06$ & 0.127 & FTO & 0 & intron \\
\hline rs8050136 & 16 & $2.68 \mathrm{E}-06$ & 0.126 & FTO & 0 & intron \\
\hline rs527248 & 1 & $2.98 \mathrm{E}-06$ & 0.237 & SEC16B & 22,728 & down $30 \mathrm{k}$ \\
\hline rs7193144 & 16 & $3.3 \mathrm{E}-06$ & 0.126 & FTO & 0 & intron \\
\hline \multicolumn{7}{|l|}{ Hypertension } \\
\hline rs17249754 & 12 & $1.07 \mathrm{E}-07$ & 0.374 & ATP2B1 & 10,742 & up $20 \mathrm{k}$ \\
\hline rs7136259 & 12 & $1.7 \mathrm{E}-07$ & 0.381 & ATP2B1 & 31,344 & up $40 \mathrm{k}$ \\
\hline rs1378942 & 15 & $2.81 \mathrm{E}-07$ & 0.172 & CSK & 0 & intron \\
\hline rs11066280 & 12 & $7.15 \mathrm{E}-06$ & 0.172 & PTPN11 & 38,753 & up $40 \mathrm{k}$ \\
\hline
\end{tabular}

${ }^{1}$ Nearby genes are defined as the closest genes to the SNP within signal boundary or the closest genes within a 200-kb window.

MAF, minor allele frequency; BMI, body mass index.

A total of seven SNPs from four genes were identified for BMI. The four genes are LOC729076, FTO, DDIT4, and SEC16B, and four SNPs, including rs9939609, which was shown for the subscapular analysis, were from the FTO gene. SEC16B polymorphisms were previously reported to be associated with obesity and obesity-induced diabetes (Hotta et al., 2009).

\section{Gene-based analysis using Fisher's combination test}

Next, we tested for the association of genes using Fisher's combination test, where a set of $p$-values for SNPs in a gene were considered simultaneously. We mapped the identified SNPs to exon/intron or within the $5-k b p$ upstream/0.5-kbp downstream regions of the known genes. In total, 31,207 genes were annotated among 327,872 SNPs. The P-values of the genes were calculated by Fisher's combination test. The numbers of 
genes that were significantly associated with a p-value less than $1.0 \mathrm{e}-5$ were selected. From the analysis, we could find that a large portion of significant genes contained insignificant SNPs. This shows that joint analysis of multiple loci within a gene can have more power, when a single SNP does not have a strong effect on complex diseases.

For subscapular, 33 genes were found to be associated. For subscapular, 54 genes were detected. Sixty-nine genes showed a strong association with BMI. Hypertension had 75 genes showing a strong association. The gene-based approach detected more genes in common within the four phenotypes than the single-marker association analyses. Three genes, SH3RF3, c12ORF51, and ATG10, were detected to be shared with hypertension and BMI. BMI and suprailiac shared 13 genes, BMl and suprailiac had 8 genes in common. Thus, subscapular and BMI had a much greater number of associated genes in common than suprailiac and BMI. Subscapular and suprailiac had 9 genes in common. BMI, subscapular, and suprailiac had PDIA6 and SNX9 in common (Table 3). The PDIA6 gene encodes a protein disulfide isomerase family member protein and localizes in the endoplasmic reticulum (ER). The role of this gene, related to obesity, has been discussed in the aspect of one of the adipocyte extracellular matrix (ECM) processing enzymes (Mariman and Wang, 2010), which partly explains the association between SNPs in PDIA6 and obesity-related traits in common.

\section{Pathway-based analysis using Fisher's exact test}

In order to determine the biological pathways that are associated with the four traits, we conducted tests on whether a pathway was enriched with the significant genes identified from the gene-based analysis. Our pathway-based analysis was conducted using 465 path- ways retrieved from the Kyoto Encyclopedia of Genes and Genomes (KEGG; www.genome.jp/kegg/), BioCarta (www.biocarta.com/), and GenMAPP (http://www.genmapp. org/) databases. Table 4 shows the significant pathways for each phenotype, identified using p-values from Fisher's exact test. Eighteen significant pathways were detected for BMI, 23 significant pathways for hypertension, 16 significant pathways for suprailiac, and 17 significant pathways for subscapular. MAPK signaling pathway was shown to be common for all of the four analyzed traits. Hypertension, subscapular, and suprailiac had calcium signaling pathway in common.

MAPK signaling pathway is one of the most ubiquitous signal transduction systems. The role of JNK-MAPK signaling in obesity was reported by multiple studies (Bost et al., 2005; Hirosumi et al., 2002). In addition, the MAPK signaling pathway is claimed to be related to cardiac hypertrophy through the Grb2 adapter protein and cardiac p38 MAPK signaling. Human cardiac hypertrophy is a common condition that often develops as a by-product of hypertension or valvular heart disease (Zhang et al., 2003).

The calcium signaling pathwayis a well-known target for treatment of hypertension (Berridge, 1994). Recently, calcium signaling in obesity was also studied and reported to have a role in determining the cell fate of adipocytes (Sergeev, 2009).

\section{SEM Analysis}

In this analysis, SEMs were used to equate causal relationships between genetic networks and correlated phenotypes based on the analysis results in the previous stages. We constructed SEMs, including the MAPK signaling pathway, which appears to be significantly common for every phenotype. SNPs were chosen within genes from the MAPK signaling pathwaywith $p$-values less than 1.0e-04 for each phenotype. In the models,

Table 3. Genes detected to be significantly associated with more than two traits from a gene-based association test. Genes having P-values $<1.0 \mathrm{E}-5$ from Fisher's combination test were considered to be significant. The numbers of significant genes were 55 for subscapular (SUB), 54 for suprailiac (SUP), 69 for BMI, and 75 for hypertension (HTN)

\begin{tabular}{ll}
\hline \multicolumn{1}{c}{ Traits } & \multicolumn{1}{c}{ Significant genes in common } \\
\hline Obesity & \\
SUB+SUP & PDIA6, SNX9 LOC, SNX9, FBXL20, SUCLG2, hCG_1981, BMPR1B, COMMD10, DOCK10 \\
BMI+SUB & PDIA6, LOC34134, JAKMIP2, PADI2, GLI3, SNX9 LOC, PARD3B, SNX9, NUP205, FTO, CDC123, TULP4, INDOL1 \\
BMI+SUP & PDIA6, DMGDH, SSBP3, SNX9 LOC, MACF1, SNX9, PGCP, AUTS2 \\
Obesity and hypertension \\
BMI+HTN & SH3RF3, C12orf51, ATG10 \\
SUB+HTN & FBXL20, HSD17B12 \\
SUP+HTN & DCC, FBXL20, SRPK1, FBXL17 \\
\hline
\end{tabular}

Genes significant at more than two traits are written in bold. 
Table 4. Pathways significantly enriched for genes associated with one of the four traits. p-values obtained from Fisher's exact test based on hypergeometric distribution

\begin{tabular}{|c|c|c|c|}
\hline Name of Pathway & p-value & Name of Pathway & p-value \\
\hline Suprailiac & & Subscapular & \\
\hline VEGF_SIGNALING_PATHWAY & 0.0007 & METHANE_METABOLISM & 0.00462 \\
\hline CELL_ADHESION_MOLECULES & 0.0091 & CARBON_FIXATION & 0.00515 \\
\hline ADHERENS_JUNCTION & 0.0044 & REDUCTIVE_CARBOXYLATE_CYCLE & 0.00521 \\
\hline PURINE_METABOLISM & 0.0079 & THIAMINE_METABOLISM & 0.00629 \\
\hline GAP_JUNCTION & 0.045 & RIBOFLAVIN_METABOLISM & 0.0089 \\
\hline COMPLEMENT_AND_COAGULATION_CASCADES & 0.0231 & VITAMIN_B6_METABOLISM & 0.01248 \\
\hline ANTIGEN_PROCESSING_AND_PRESENTATION & 0.0043 & BIOTIN_METABOLISM & 0.01257 \\
\hline RENIN_AN̄GIOTENSIN_SYSTEM & 0.0079 & LIPOIC_ACID_METABOLISM & 0.01409 \\
\hline CALCIUMM_SIGNALING_PATHWAY & 0.0079 & CALCIUMMSIḠNALING_PATHWAY & 0.01456 \\
\hline HEMATOPOIETIC_CELL_LINEAGE & 0.0208 & RETINOL_METABOLISM & 0.01514 \\
\hline MAPK_SIGNALING_PATHWAY & 0.0208 & PORPHYRIN_AND_CHLOROPHYLL_METABOLISM & 0.01664 \\
\hline B_CELL_RECEPTOR_SIGNALING_PATHWAY & 0.0079 & LIMONENE_AND_PINENE_DEGRADATION & 0.01682 \\
\hline FC_EPSILON_RI_SIGNALING_PATHWAY & 0.0128 & PHENYLPROPANOID_BIOSYNTHESIS & 0.0208 \\
\hline CIRCADIAN_RHYTHM & 0.0208 & ALKALOID_BIOSYNTHESIS_I & 0.02288 \\
\hline \multirow[t]{3}{*}{ LONG_TERM_POTENTIATION } & 0.0445 & AMINOACYL_TRNA_BIOSYNTHESIS & 0.0308 \\
\hline & & MAPK_SIGNALING_PATHWAY & 0.03288 \\
\hline & & GLYCAN_STRUCTURES_DEGRADATION & 0.04424 \\
\hline$B M I$ & & Hypertension & \\
\hline GLYCOLYSIS_AND_GLUCONEOGENESIS & 0.0005 & HISTIDINE_METABOLISM & 0.00007 \\
\hline CITRATE_CYCLE & 0.00515 & GAMMA_HEXACHLOROCYCLOHEXANE_DEGRADATION & 0.00044 \\
\hline PENTOSE_PHOSPHATE_PATHWAY & 0.00629 & BISPHENOELA_DEGRADATION & 0.00079 \\
\hline INOSITOL_METABOLISM & 0.00629 & TRYPTOPHAN_METABOLISM & 0.00079 \\
\hline PENTOSE_AND_GLUCURONATE_INTERCONVERSIONS & 0.0089 & PHENYLALANINE_TYROSINE_AND_TRYPTOPHAN_BIOSYNTHESIS & 0.00091 \\
\hline FRUCTOSE_AND_MANNOSE_METABOLISM & 0.01248 & NOVOBIOCIN_BIOSYNTHESIS & 0.00148 \\
\hline GALACTOSE_METABOLISM & 0.01456 & SELENOAMINO_ACID_METABOLISM & 0.00208 \\
\hline FATTY_ACID_METABOLISM & 0.0208 & GLUTATHIONE_METABOLISM & 0.00231 \\
\hline SYNTHESIS_AND_DEGRADATION_OF_KETONE_BODIES & 0.02521 & NAPHTHALENE_AND_ANTHRACENE_DEGRADATION & 0.00233 \\
\hline BIOSYNTHESIS_OF_STEROIDS & 0.02665 & 1,4_DICHLOROBENZENE_DEGRADATION & 0.00246 \\
\hline BILE_ACID_BIOSYNTHESIS & 0.03121 & ETHYLBENZENE_DEGRADATION & 0.00445 \\
\hline MAPK_SIGNALING_PATHWAY & 0.03187 & BUTANOATE_METABOLISM & 0.00446 \\
\hline ANDROGEN_AND_ESTROGEN_METABOLISM & 0.03329 & MAPK_SIGNALING_PATHWAY & 0.0045 \\
\hline OXIDATIVE_PHOSPHORYLATION & 0.03953 & THIAMINE_METABOLISM & 0.00549 \\
\hline UREA_CYCLE_AND_METABOLISM_OF_AMINO_GROUPS & 0.0402 & VITAMIN_BE_METABOLISM & 0.00808 \\
\hline CAFFEINE_METABOLISM & 0.04429 & BIOTIN_METABOLISM & 0.00886 \\
\hline \multirow[t]{6}{*}{ GLUTAMATE_METABOLISM } & 0.04848 & LIPOIC_ACID_METABOLISM & 0.01455 \\
\hline & & RETINOL_METABOLISM & 0.01808 \\
\hline & & CALCIUM_SIGNALING_PATHWAY & 0.0267 \\
\hline & & MONOTERPENOID_BIOSYNTHESIS & 0.03128 \\
\hline & & SULFUR_METABOLISM & 0.03222 \\
\hline & & CAPROLACTAM_DEGRADATION & 0.04888 \\
\hline
\end{tabular}

the pathway was treated as a latent variable, and SNPs and four phenotypes were the observed variables. Two models were considered, as shown in Fig. 1. Model 1 assumes that suprailiac and subscapular influence BMI and that BMI influences hypertension. Model 2 assumes that suprailiac, subscapular, and BMI influence hypertension simultaneously.

In an SEM, the goodness-of-fit index (GFI) measures the relative differences between the data and estimated values obtained from a model, while the adjusted GFI (AGFI) adjusts the GFI according to the degrees of freedom. If these two measures are close to 1 , we can conclude that the model fits the data well. The Akaike information criterion (AIC) is a well-known measure that can be used for model comparisons. The smaller the AIC, the better the model is. Three types of goodness-of-fit measures were evaluated to select the best model of the two models: for model 1, GFI $=0.791$, $A G F I=0.793$, and $A I C=1132.005$; and for model 2, $\mathrm{GFI}=0.774, \mathrm{AGFI}=0.776$, and $\mathrm{AIC}=1290.599$. In general, models with GFI and AGFI measures closer to 1 and with smaller AICs are considered to fit well. As GFI and AGFI were close to 1 for both models, both models fit the data well. But, model 1 showed a bigger GFI and 
(a) Model 1.

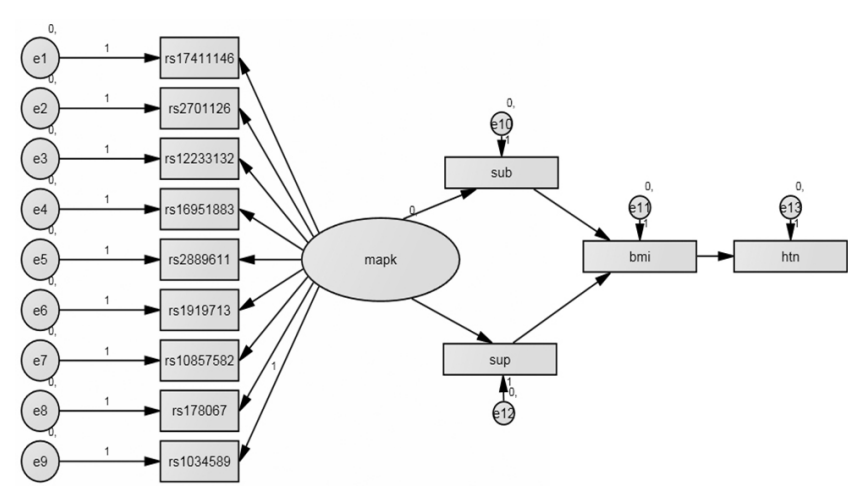

Fig. 1. Structural equation models.

AGFI with a smaller AIC than model 2; model 1 was selected to be the final model. Through a comparison between two models, we concluded that suprailiac and subscapular indirectly affect hypertension susceptibility by influencing BMI.

\section{Discussion}

Most GWASs have focused on single-SNP analyses of single traits. The result of a single-SNP analysis is limited to correlations between candidate susceptible loci and single traits. In this study, we conducted a geneand pathway-based analysis beyond single-SNP analysis. Based on the gene- and pathway-based analysis, we proposed the use of SEMs to construct a model for causal relationships among genetic factors and risk factors in terms of traits through an underlying biological pathway.

The gene-based analysis detected more significant genes than the single-SNP analysis. We demonstrate that gene-based analysis is a powerful method to detect genes that are associated with traits. A gene-based analysis is also easier to interpret, as function and the relevant disease with a gene are better investigated than a SNP.

A pathway-based analysis was conducted to find pathways that were significantly correlated with each phenotype. In our analysis, a pathway that was associated with four traits in common was detected. Pathway-based analysis provides a more comprehensive understanding of the biological process of complex traits than a gene-based or single-SNP analysis.

SEM was used to identify the relationship among risk factors of a complex trait. In this study, SEMs were used to model how upper body fat distribution, represented by suprailiac and subscapular, and average body (b) Model 2.

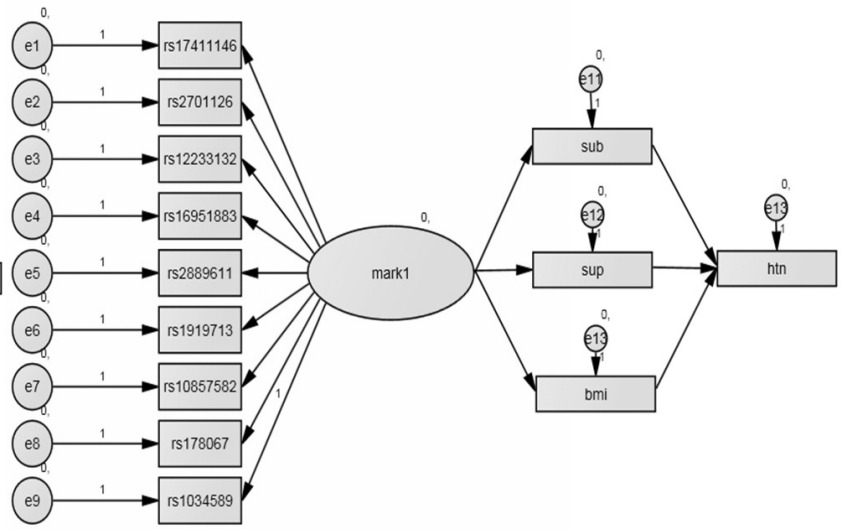

fat distribution, represented by BMI, were related with hypertension. Although we fit a limited number of SEMs, we demonstrated that SEM analysis is useful in investigating complex biological phenomena, because it allows us to present complex causal relationships in equations and express them in path diagrams and because it deals better with correlated variables that occur frequently in biological data.

However, SEM has some limitations. It requires an initial model to start with. SEM is constructed under strict multivariate normality and independence assumptions among errors. Another difficulty is that run time increases substantially as the number of variables increases.

\section{Acknowledgments}

This work was supported by the Consortium for Large-Scale Genome-Wide Association Study, National Research Foundation (KRF-2008-313-C00086), and the Brain Korea 21 Project of the Ministry of Education. The KARE data analyzed in this study were obtained from the Korean Genome Analysis Project (4845-301), which was funded by a grant from the Korea National Institute of Health (Korea Center for Disease Control, Ministry for Health, Welfare and Family Affairs), Republic of Korea. The authors thank Hyung-Lae Kim (Center for Genome Science, National Institute of Health, South Korea), Nam $\mathrm{H}$. Cho (Department of Preventive Medicine, Ajou University, South Korea), and Chol Shin (Department of Internal Medicine, Korea University Ansan Hospital, South Korea) for their great efforts in generating and providing these valuable data. 


\section{References}

Baranzini, S.E., Galwey, N.W., Wang, J., Khankhanian, P., Lindberg, R., Pelletier, D., Wu, W., Uitdehaag, B.M., Kappos, L., Polman, C.H., Matthews, P.M., Hauser, S.L., Gibson, R.A., Oksenberg, J.R., and Barnes, M.R. (2009). Pathway and network-based analysis of genome-wide association studies in multiple sclerosis. Hum. Mol. Genet. 18, 2078-2090.

Berridge, M.J. (1994). The biology and medicine of calcium signalling. Mol. Cell Endocrinol. 98, 119-124.

Bost, F., Aouadi, M., Caron, L., and Binetruy, B. (2005). The role of MAPKs in adipocyte differentiation and obesity. Biochimie 87, 51-56.

Cho, Y.S., Go, M.J., Kim, Y.J., Heo, J.Y., Oh, J.H., Ban, H.J., Yoon, D., Lee, M.H., Kim, D.J., Park, M., Cha, S.H., Kim, J.W., Han, B.G., Min, H., Ahn, Y., Park, M.S., Han, H.R., Jang, H.Y., Cho, E.Y., Lee, J.E., Cho, N.H., Shin, C., Park, T., Park, J.W., Lee, J.K., Cardon, L., Clarke, G., McCarthy, M.I., Lee, J.Y., Oh, B., and Kim, H.L. (2009). A large-scale genome-wide association study of Asian populations uncovers genetic factors influencing eight quantitative traits. Nat. Genet. 41, 527-534.

Dustan, H. (1991). Obesity and hypertension. Diabetes Care 14, 488-504.

Fisher, R.A. (1925). Statistical methods for research workers. Oliver and Lloyd, London.

Frayling, T.M., Timpson, N.J., Weedon, M.N., Zeggini, E., Freathy, R.M., Lindgren, C.M., Perry, J.R., Elliott, K.S., Lango, H., Rayner, N.W., Shields, B., Harries, L.W., Barrett, J.C., Ellard, S., Groves, C.J., Knight, B., Patch, A.M., Ness, A.R., Ebrahim, S., Lawlor, D.A., Ring, S.M., Ben-Shlomo, Y., Jarvelin, M.R., Sovio, U., Bennett, A.J., Melzer, D., Ferrucci, L., Loos, R.J., Barroso, I., Wareham, N.J., Karpe, F., Owen, K.R., Cardon, L.R., Walker, M., Hitman, G.A., Palmer, C.N., Doney, A.S., Morris, A.D., Smith, G.D., Hattersley, A.T., and McCarthy, M.I. (2007). A common variant in the FTO gene is associated with body mass index and predisposes to childhood and adult obesity. Science 316, 889-894.

Hirosumi, J., Tuncman, G., Chang, L., Gorgun, C.Z., Uysal, K.T., Maeda, K., Karin, M., and Hotamisligil, G.S. (2002). A central role for JNK in obesity and insulin resistance. Nature 420, 333-336.

Hong, K.W., Go, M.J., Jin, H.S., Lim, J.E., Lee, J.Y., Han, B.G., Hwang, S.Y., Lee, S.H., Park, H.K., Cho, Y.S., and Oh, B. (2010). Genetic variations in ATP2B1, CSK, ARSG and CSMD1 loci are related to blood pressure and/or hypertension in two Korean cohorts. J. Hum. Hypertens. 24, 367-372

Hotta, K., Nakamura, M., Nakamura, T., Matsuo, T., Nakata, Y., Kamohara, S., Miyatake, N., Kotani, K., Komatsu, R., Itoh, N., Mineo, I., Wada, J., Masuzaki, H., Yoneda, M., Nakajima, A., Funahashi, T., Miyazaki, S., Tokunaga, K., Kawamoto, M., Ueno, T., Hamaguchi, K., Tanaka, K., Yamada, K., Hanafusa, T., Oikawa, S., Yoshimatsu, H., Nakao, K., Sakata, T., Matsuzawa, Y., Kamatani, N., and, Y.N. (2009). Association between obesity and polymorphisms in SEC16B, TMEM18, GNPDA2, BDNF, FAIM2 and MC4R in a Japanese population. J. Hum. Genet. 54, 727-731.

Kolz, M. (2008). Association between variations in the TLR4 gene and incident type 2 diabetes is modified by the ratio of total cholesterol to HDL-cholesterol. BMC Med. Genet. 25, 9 .

Kraft, P., and Raychaudhuri, S. (2009). Complex diseases, complex genes: keeping pathways on the right track. Epidemiology 20, 508-511.

Lesnick, T.G., Papapetropoulos, S., Mash, D.C., FfrenchMullen, J., Shehadeh, L., de Andrade, M., Henley, J.R., Rocca, W.A., Ahlskog, J.E., and Maraganore, D.M. (2007). A genomic pathway approach to a complex disease: axon guidance and Parkinson disease. PLOS Genet, 3, e98.

Levy, D., Ehret, G.B., Rice, K., Verwoert, G.C., Launer, L.J., Dehghan, A., Glazer, N.L., Morrison, A.C., Johnson, A.D., Aspelund, T., Aulchenko, Y., Lumley, T., Kottgen, A., Vasan, R.S., Rivadeneira, F., Eiriksdottir, G., Guo, X., Arking, D.E., Mitchell, G.F., Mattace-Raso, F.U., Smith, A.V., Taylor, K., Scharpf, R.B., Hwang, S.J., Sijbrands, E.J., Bis, J., Harris, T.B., Ganesh, S.K., O'Donnell, C.J., Hofman, A., Rotter, J.I., Coresh, J., Benjamin, E.J., Uitterlinden, A.G., Heiss, G., Fox, C.S., Witteman, J.C., Boerwinkle, E., Wang, T.J., Gudnason, V., Larson, M.G., Chakravarti, A., Psaty, B.M., and van Duijn, C.M. (2009). Genome-wide association study of blood pressure and hypertension. Nat. Genet. 41, 677-687.

Licata, G., Scaglione, R., Ganguzza, A., Corrao, S., Donatelli, M., Parrinello, G., Dichiara, M.A., Merlino, G., and Cecala, M.G. (1994). Central obesity and hypertension. Relationship between fasting serum insulin, plasma renin activity, and diastolic blood pressure in young obese subjects. Am. J. Hypertens. 7, 314-320

Mariman, E.C., and Wang, P. (2010). Adipocyte extracellular matrix composition, dynamics and role in obesity. Cell Mol. Life Sci. 67, 1277-1292.

Niskanen, L., Laaksonen, D.E., Nyyssönen, K., Punnonen, $\mathrm{K}$., Valkonen, V.-P., Fuentes, $\mathrm{R}$, Tuomainen, T.-P., Salonen, R., and Salonen, J.T. (2004). Inflammation, abdominal obesity, and smoking as predictors of hypertension. Hypertension 44, 859-865.

Purcell, S., Neale, B., Todd-Brown, K., Thomas, L., Ferreira, M.A., Bender, D., Maller, J., Sklar, P., de Bakker, P.I., Daly, M.J., and Sham, P.C. (2007). PLINK: a tool set for whole-genome association and population-based linkage analyses. Am. J. Hum. Genet. 81, 559-575

Rajagopalan, D., and Agarwal, P. (2005). Inferring pathways from gene lists using a literature-derived network of biological relationships. Bioinformatics 21, 788-793.

Rioux, J.D., Xavier, R.J., Taylor, K.D., Silverberg, M.S., Goyette, P., Huett, A., Green, T., Kuballa, P., Barmada, M.M., Datta, L.W., Shugart, Y.Y., Griffiths, A.M., Targan, S.R., Ippoliti, A.F., Bernard, E.J., Mei, L., Nicolae, D.L., Regueiro, M., Schumm, L.P., Steinhart, A.H., Rotter, J.I., Duerr, R.H., Cho, J.H., Daly, M.J., and Brant, S.R. (2007). Genome-wide association study identifies new susceptibility loci for Crohn disease and implicates au- 
tophagy in disease pathogenesis. Nat. Genet. 39, 596604.

Saxena, R., Voight, B.F., Lyssenko, V., Burtt, N.P., de Bakker, P.I., Chen, H., Roix, J.J., Kathiresan, S., Hirschhorn, J.N., Daly, M.J., Hughes, T.E., Groop, L., Altshuler, D., Almgren, P., Florez, J.C., Meyer, J., Ardlie,

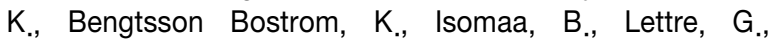
Lindblad, U., Lyon, H.N., Melander, O., Newton-Cheh, C., Nilsson, P., Orho-Melander, M., Rastam, L., Speliotes, E.K., Taskinen, M.R., Tuomi, T., Guiducci, C., Berglund, A., Carlson, J., Gianniny, L., Hackett, R., Hall, L., Holmkvist, J., Laurila, E., Sjogren, M., Sterner, M., Surti, A., Svensson, M., Tewhey, R., Blumenstiel, B., Parkin, M., Defelice, M., Barry, R., Brodeur, W., Camarata, J., Chia, N., Fava, M., Gibbons, J., Handsaker, B., Healy, C., Nguyen, K., Gates, C., Sougnez, C., Gage, D., Nizzari, M., Gabriel, S.B., Chirn, G.W., Ma, Q., Parikh, H., Richardson, D., Ricke, D., and Purcell, S. (2007). Genome-wide association analysis identifies loci for type 2 diabetes and triglyceride levels. Science 316, 1331-1336.

Scaglione, R., Ganguzza, A., Corrao, S., Parrinello, G., Merlino, G., Dichiara, M.A., Arnone, S., D'Aubert, M.D., and Licata, G. (1995). Central obesity and hypertension: pathophysiologic role of renal haemodynamics and function. Int J Obes Relat. Metab. Disord. 19, 403-409.

Selby, J.V., Friedman, G.D., and Quesenberry, C.P., Jr. (1989). Precursors of essential hypertension. The role of body fat distribution pattern. Am. J. Epidemiol. 129, 43-53.

Sergeev, I.N. (2009). Novel Mediators of Vitamin D Signaling in Cancer and Obesity, Immun., Endoc. \& Metab. Agents in Med. Chem. 9, 153-158.

Torkamani, A., Topol, E.J., and Schork, N.J. (2008). Pathway analysis of seven common diseases assessed by genome-wide association, Genomics 92, 265-272.

Willer, C.J., Speliotes, E.K., Loos, R.J., Li, S., Lindgren, C.M., Heid, I.M., Berndt, S.I., Elliott, A.L., Jackson, A.U., Lamina, C., Lettre, G., Lim, N., Lyon, H.N., McCarroll, S.A., Papadakis, K., Qi, L., Randall, J.C., Roccasecca, R.M., Sanna, S., Scheet, P., Weedon, M.N., Wheeler, E., Zhao, J.H., Jacobs, L.C., Prokopenko, I., Soranzo, N., Tanaka, T., Timpson, N.J., Almgren, P., Bennett, A., Bergman, R.N., Bingham, S.A., Bonnycastle, L.L., Brown, M., Burtt, N.P., Chines, P., Coin, L., Collins, F.S., Connell, J.M., Cooper, C., Smith, G.D., Dennison, E.M., Deodhar, P., Elliott, P., Erdos, M.R., Estrada, K., Evans, D.M., Gianniny, L., Gieger, C., Gillson, C.J., Guiducci, C., Hackett, R., Hadley, D., Hall, A.S., Havulinna, A.S., Hebebrand, J., Hofman, A., Isomaa, B., Jacobs, K.B.,
Johnson, T., Jousilahti, P., Jovanovic, Z., Khaw, K.T., Kraft, P., Kuokkanen, M., Kuusisto, J., Laitinen, J., Lakatta, E.G., Luan, J., Luben, R.N., Mangino, M., McArdle, W.L., Meitinger, T., Mulas, A., Munroe, P.B., Narisu, N., Ness, A.R., Northstone, K., O'Rahilly, S., Purmann, C., Rees, M.G., Ridderstrale, M., Ring, S.M., Rivadeneira, F., Ruokonen, A., Sandhu, M.S., Saramies, J., Scott, L.J., Scuteri, A., Silander, K., Sims, M.A., Song, K., Stephens, J., Stevens, S., Stringham, H.M., Tung, Y.C., Valle, T.T., Van Duijn, C.M., Vimaleswaran, K.S., Vollenweider, P., Waeber, G., Wallace, C., Watanabe, R.M., Waterworth, D.M., Watkins, N., Witteman, J.C., Zeggini, E., Zhai, G., Zillikens, M.C., Altshuler, D., Caulfield, M.J., Chanock, S.J., Farooqi, I.S., Ferrucci, L., Guralnik, J.M., Hattersley, A.T., Hu, F.B., Jarvelin, M.R., Laakso, M., Mooser, V., Ong, K.K., Ouwehand, W.H., Salomaa, V., Samani, N.J., Spector, T.D., Tuomi, T., Tuomilehto, J., Uda, M., Uitterlinden, A.G., Wareham, N.J., Deloukas, P., Frayling, T.M., Groop, L.C., Hayes, R.B., Hunter, D.J., Mohlke, K.L., Peltonen, L., Schlessinger, D., Strachan, D.P., Wichmann, H.E., McCarthy, M.I., Boehnke, M., Barroso, I., Abecasis, G.R., and Hirschhorn, J.N. (2009). Six new loci associated with body mass index highlight a neuronal influence on body weight regulation. Nat. Genet. 41, 25-34.

WTCCC (2007). Genome-wide association study of 14,000 cases of seven common diseases and 3,000 shared controls. Nature 447, 661-678.

Zanke, B.W., Greenwood, C.M., Rangrej, J., Kustra, R., Tenesa, A., Farrington, S.M., Prendergast, J., Olschwang, S., Chiang, T., Crowdy, E., Ferretti, V., Laflamme, P., Sundararajan, S., Roumy, S., Olivier, J.F., Robidoux, F., Sladek, R., Montpetit, A., Campbell, P., Bezieau, S., O'Shea, A.M., Zogopoulos, G., Cotterchio, M., Newcomb, P., McLaughlin, J., Younghusband, B., Green, R., Green, J., Porteous, M.E., Campbell, H., Blanche, H., Sahbatou, M., Tubacher, E., Bonaiti-Pellie, C., Buecher, B., Riboli, E., Kury, S., Chanock, S.J., Potter, J., Thomas, G., Gallinger, S., Hudson, T.J., and Dunlop, M.G. (2007). Genome-wide association scan identifies a colorectal cancer susceptibility locus on chromosome 8q24. Nat. Genet. 39, 989-994.

Zaykin, D.V., Zhivotovsky, L.A., Czika, W., Shao, S., and Wolfinger, R.D. (2007). Combining p-values in large-scale genomics experiments. Pharm. Stat. 6, 217-226.

Zhang, S., Weinheimer, C., Courtois, M., Kovacs, A., Zhang, C.E., Cheng, A.M., Wang, Y., and Muslin, A.J. (2003). The role of the Grb2-p38 MAPK signaling pathway in cardiac hypertrophy and fibrosis. J. Clin. Invest. 111, 833-841. 